\title{
GNAS NM_000516.5:C.374A>G
}

National Cancer Institute

\section{Source}

National Cancer Institute. GNAS NM 000516.5:C.374A>G. NCI Thesaurus. Code C146953.

A nucleotide substitution at position 374 of the coding sequence of the GNAS gene where adenine has been mutated to guanine. 